\title{
Transverse Distribution Calculation and Analysis of Strengthened Yingjing Bridge
}

\author{
Liao Xiaofang $^{1} \&$ Li Dongdong ${ }^{1}$ \\ ${ }^{1}$ Department of Civil engineering, Chongqing Jiaotong University, Chongqing, China \\ Correspondence: Liao Xiaofang, Department of Civil engineering, Chongqing Jiaotong University, Chongqing \\ 400074, China. Tel: 86-136-2844-4207. E-mail: 290943158@qq.com
}

Received: February 28, 2014

Accepted: March 26, $2014 \quad$ Online Published: April 23, 2014

doi:10.5539/mas.v8n3p107

URL: http://dx.doi.org/10.5539/mas.v8n3p107

\begin{abstract}
Box-girder has been adopted to strengthen bridge as large border girder, in which the original girders can be unloaded with box-girder bearing most loads. However, the load transverse distribution calculation method for it is still imperfect thus a modified calculation method is specially proposed to calculate the load transverse distribution in this case basing on existed methods. An engineering example is introduced to describe the calculation process and corresponding FEM model is established to validate the feasibility and applicability of this calculation method. Besides, comparisons between the load transverse distribution before and after strengthened are conducted which further proves that adding box-girder to the original bridge is an effective strengthening way.
\end{abstract}

Keywords: bridge strengthening, load transverse distribution, calculation method, box-girder

\section{Introduction}

Nowadays, strengthening the original bridge by adding large border girder to original girders has been a new tendency in bridge strengthening engineering (Wu \& Zheng, 1997). According to the theory that the greater stiffness the girder obtains the more loads it will be subjected to, the risks of original girders can be greatly decreased with large border girder bearing most loads in this condition. So box-girder is naturally preferred as large border girder for strengthening to bear most loads due to its superior bending and torsional stiffness, which has been applied in practical engineering (Nie et al., 2010). Actually, the essential mechanism that this strengthening method works is that the transverse load is redistributed after adding box girder as large border girder. Therefore, exploring the new load transverse distribution becomes particularly necessary for both design and construction. Rigid connected girder method (Fan, 2001; He \& Xie, 1996; Li \& Shi, 1977) is usually used to calculate the load transverse distribution of assembly T-girder bridge but it can't be used in this condition since the differences of girder size and stiffness can't be taken into consideration.

Nie has proposed a method basing on rigid connected girder method to calculate the load transverse distribution and the cross section diagram of the bridge cited in his paper is shown in Figure 1. In that case, the box-girder is regarded as a large T-girder whose deformation is neglected which makes the results not that correct especially when the box-girder is large to some extent. Therefore, to more accurately calculate the load transverse distribution when strengthening with box-girder, a modified method is proposed in this paper on the basis of existed methods, in which the box-girder is divided into two T-girders with bending stiffness and torsional stiffness equally distributed to them, whose deformation can be taken into consideration.

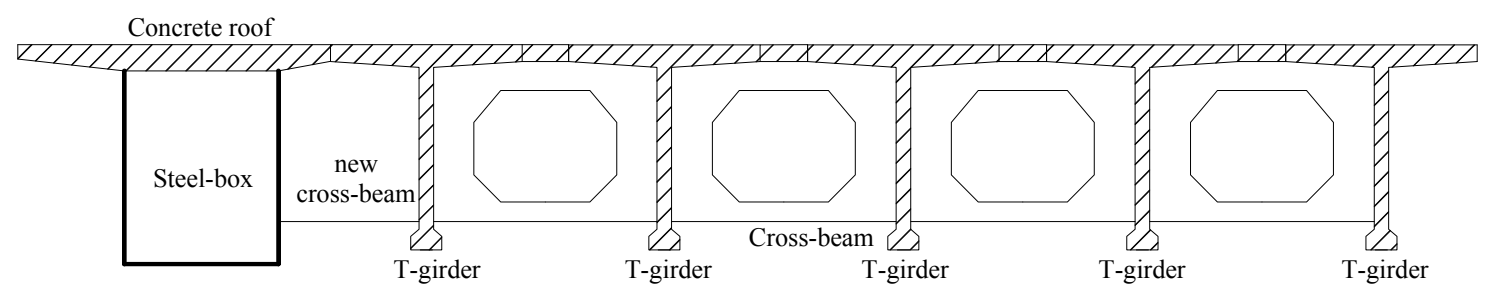

Figure 1. Cross section of bridge in Nie's paper 
Calculation mechanism and process of this modified method are described relying on the strengthening project of Yingjing bridge (Zhou \& Zhang, 1998; D. Zhang, J. Zhang, \& Fan, 2003), whose FEM model is then established (Hambly, 1982) using grillage method to validate the applicability and feasibility of this calculation method. And then, comparisons between the load transverse distribution of Yingjing Bridge before and after strengthened are conducted which further proves that adding box-girder to the original bridge is an effective strengthening way to avoid cracks and improve the bearing capacity.

\section{Project Summary}

Yingjing Bridge, as a part of National Route 108, is the only bridge crossing Jing River in Sichuan province, China and completed in 1965. This bridge is $111.5 \mathrm{~m}$ in length and consists of 6 simply supported beams, with each span of $16.8 \mathrm{~m}$ (Figure 2). Cross section diagram of the simply supported beam is shown in Figure 3.

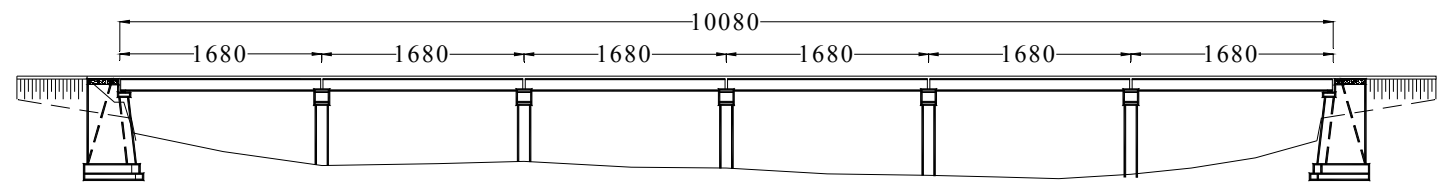

Figure 2. General arrangement diagram of Yingjing Bridge (unit: $\mathrm{cm}$ )

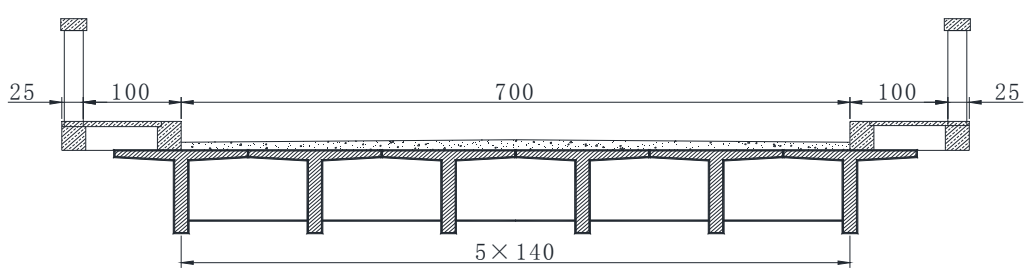

Figure 3. Cross section diagram of Yingjing Bridge (unit: $\mathrm{cm}$ )

Due to high traffic, many cracks were found in this bridge and most cracks are wide (the maximum of $2.0 \mathrm{~mm}$ ) and concentrated especially to those of the T-girders lower edge. Hence, the bridge bearing capacity deduced greatly being only about $90 \%$ of the design that it was strengthened and broadened in June, 1997 to meet the increasing traffic requirements by adding two large box girders on both sides. The added box girder is reinforcement concrete, $3.55 \mathrm{~m}$ in width and $1.20 \mathrm{~m}$ in height (Figure 4(a)) whose detail size are shown in Figure 4(b) and (c).
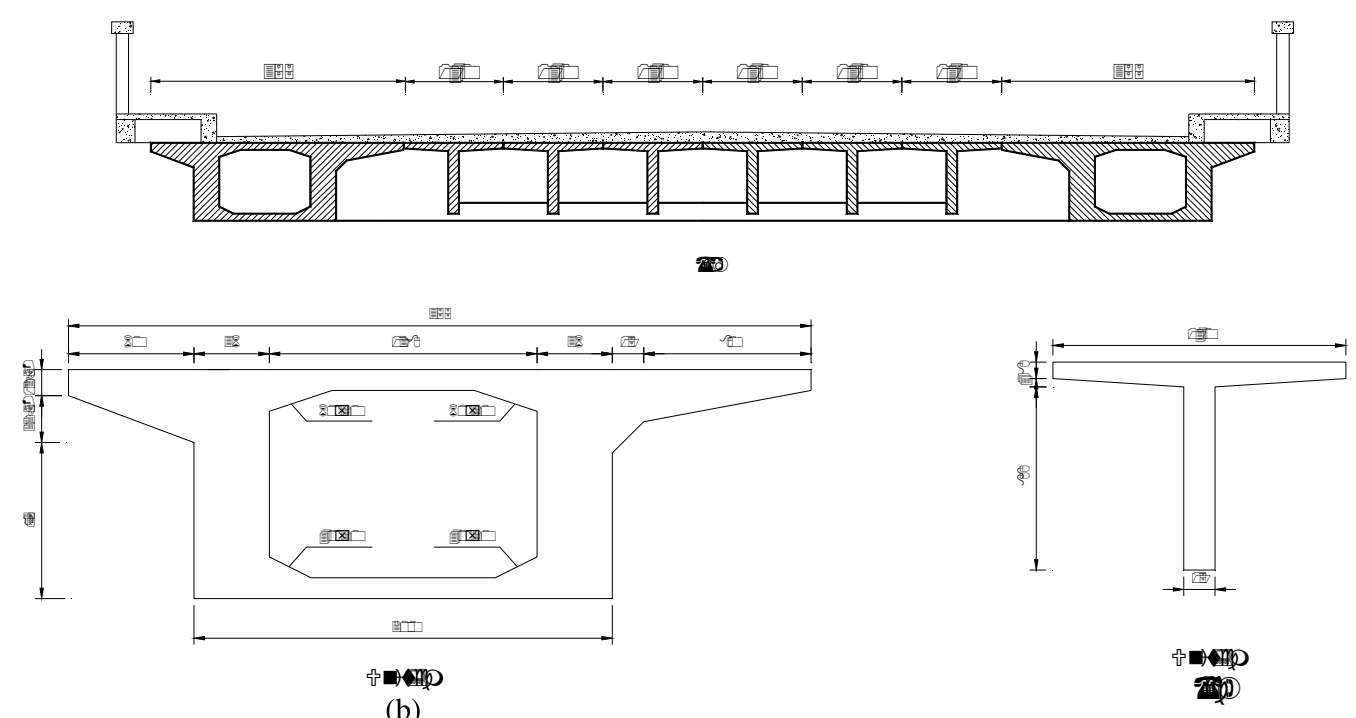

Figure 4. Cross section diagram of Yingjing Bridge after strengthened (unit: $\mathrm{cm}$ ) 


\section{Analysis on Transverse Distribution of Yingjing Bridge}

\subsection{Calculation Process}

To accurately calculate the load transverse distribution of the bridge after strengthened, divide the box girder into two T-girders with bending stiffness and torsional stiffness equally distributed (Figure 5) so that the box-girder deformation can be taken into consideration. It is worth noting that the centroids of the simplified T-girders should be overlapped with the box-girder to better keep the mechanic states and we can take the flange thickness of $1 / 3$ section as the whole flange thickness when the flange thickness changed linearly. Transverse connections between each girder are separated along longitudinal replaced by vertical shear force and pure moment when main girder is subjected to the unit load (Figure 6). Then according to the principle of virtual work, the statically indeterminate canonical equation can be established as follows.

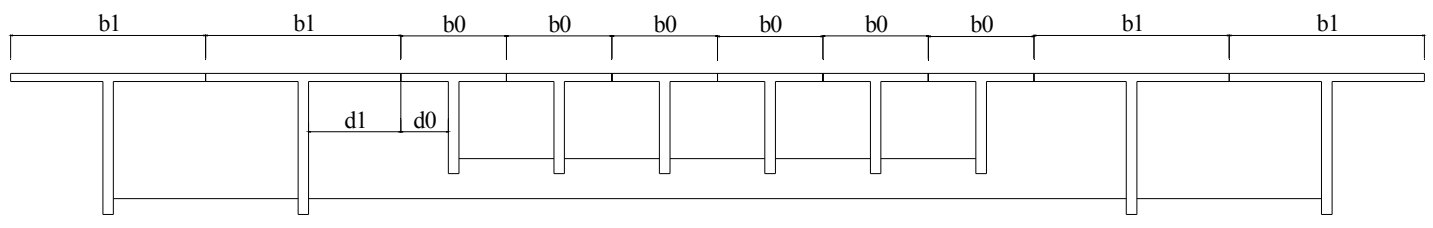

Figure 5. Calculation model of transverse distribution

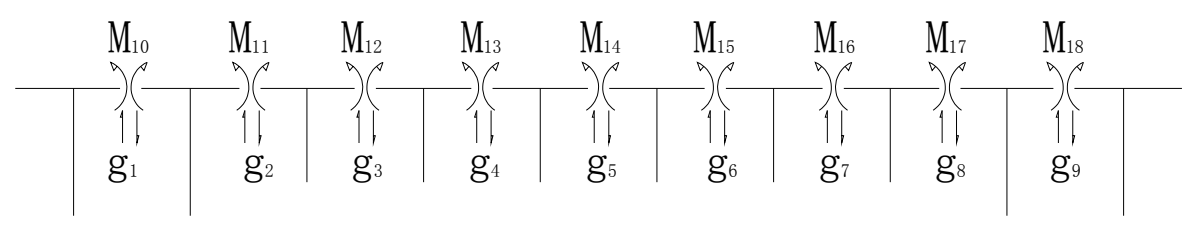

Figure 6. Redundant shear force and moment between girders

$$
\begin{aligned}
& \sum_{m=1,2 \ldots 9} \delta_{i m} \cdot g_{m}+\sum_{n=10,11 \ldots 18} \delta_{i n} \cdot M_{n}+\delta_{i p}{ }^{k}=0 \\
& (i=1,2, \ldots, 17,18 ; m=1,2 \ldots, 9 ; n=10,11, \ldots, 18 ; k=1,2 . .10)
\end{aligned}
$$

Where $\delta_{i j}$ means the structural flexibility coefficient, representing the deflection happens in the direction of redundant force $\mathrm{i}$ when redundant force $\mathrm{j}$ is unit load. And according to elastic reciprocal theory, $\delta_{i j}=\delta_{j i}$. $\delta_{i p}{ }^{k}$ equals to the deflection of beam $i$ when unit load acts at girder $k ; g_{m}$ and $M_{n}$ mean redundant shear and moment respectively. We can obtain all the $\delta_{i j}$ and $\delta_{i p}{ }^{k}$ according to static equilibrium. Schematic diagram of calculating flexibility coefficient $\delta_{11}$ and $\delta_{10,10}$ is shown in Figure 7.

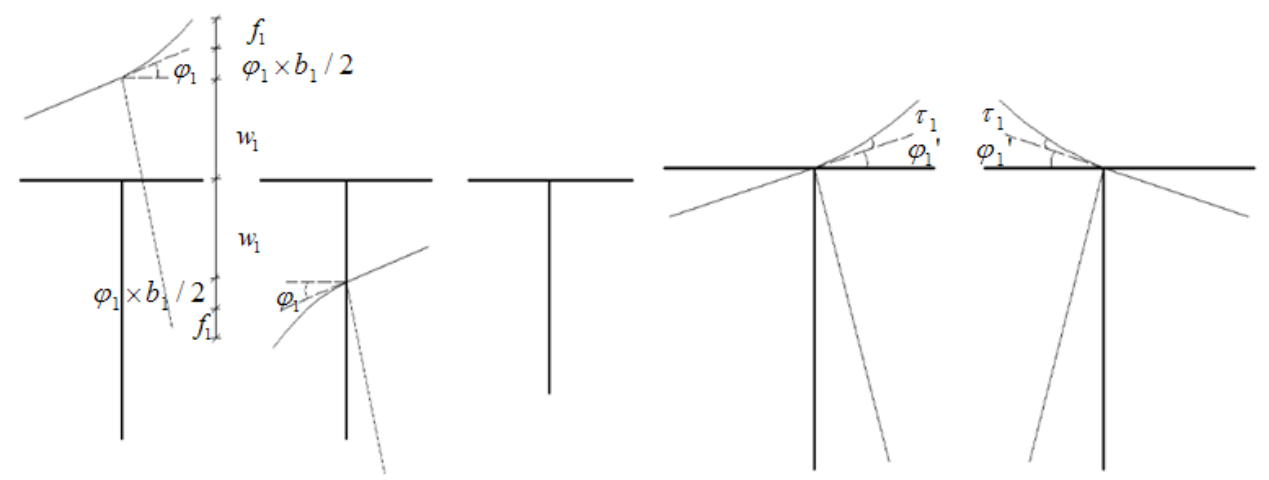

Figure 7. Schematic diagram of flexibility coefficient $\delta_{11}$ and $\delta_{10,10}$ 


$$
\begin{aligned}
& \delta_{11}=\delta_{99}=2\left(w_{1}+\varphi_{1} \cdot \frac{b_{1}}{2}+f_{1}\right) ; \quad \delta_{22}=\delta_{88}=w_{1}+\varphi_{1} \cdot \frac{b_{1}}{2}+f_{1}+w_{0}+\varphi_{0} \cdot \frac{b_{0}}{2}+f_{0} \\
& \delta_{33}=\delta_{44}=\delta_{55}=\delta_{66}=\delta_{77}=2\left(w_{0}+\varphi_{0} \cdot \frac{b_{0}}{2}+f_{0}\right) ; \quad \delta_{12}=\delta_{89}=-\left(w_{1}-\varphi_{1} \cdot \frac{b_{1}}{2}\right) \\
& \delta_{23}=\delta_{34}=\delta_{45}=\delta_{56}=\delta_{67}=-\left(w_{0}-\varphi_{0} \cdot \frac{b_{0}}{2}\right) ; \quad \delta_{10,10}=\delta_{18,18}=2\left(2 \varphi_{1} / b_{1}+\tau_{1}\right) \\
& \delta_{11,11}=\delta_{17,17}=\left(2 \varphi_{1} / b_{1}+\tau_{1}+2 \varphi_{0} / b_{0}+\tau_{0}\right) ; \quad \delta_{12,12}=\ldots=\delta_{16,16}=2\left(2 \varphi_{0} / b_{0}+\tau_{0}\right) \\
& \delta_{1,11}=\delta_{8,18}=\varphi_{1}=-\delta_{2,10} ; \delta_{2,11}=\varphi_{1}-\varphi_{0}=-\delta_{8,17} ; \quad \delta_{2,12}=\delta_{3,13}=\delta_{4,14}=\delta_{5,15}=\delta_{6,16}=\delta_{7,17}=\varphi_{0}
\end{aligned}
$$

The other flexibility coefficients are all zero.

Where $b_{0}, b_{1}$ stands for the width of the inner and border girder while $d_{0}, d_{1}$ stands for the flange length of the inner and border girder; $w_{0}, \varphi_{0}$, and $\tau_{0}$ respectively represent the girder deflection under unit load, rotating angle, cantilever deflection under shear force and cantilever deflection under moment of the inner-girder. Accordingly, $w_{1}, \varphi_{1}, f_{1}$ and $\tau_{1}$ respectively represent similar parameter of the border girder. $I_{t r 1}$ and $I_{t r 0}$ are respectively the bending stiffness of the girder in lateral direction which consist of the bending stiffness of the diaphragms and the one of roof. $k_{1}=I_{1} / I_{0}, k_{2}=I_{t 1} / I_{t 0}$ respectively mean the bending inertia ratio and torsional inertia ratio between the large border-girder and the inner girder. $k_{3}=b_{1} / b_{0}, k_{4}=d_{1} / d_{0}$ respectively mean the flange width ratio and cantilever length of the border-girder to the inner girder.

$\gamma_{0}=5.8 \frac{I_{0}}{I_{t 0}}\left(\frac{b_{0}}{l}\right)^{2}$ stands for the ratio parameter between bending inertia and torsional inertia of the inner girder, $\beta_{0}=\frac{\pi^{4}}{3} \frac{I_{0}}{l^{4}} \frac{d_{0}^{3}}{I_{t r 0}}$ stands for the bending inertia ratio parameter between the longitudinal direction and transverse direction of girder. Similarly, $\gamma_{1}=k_{3}{ }^{2} \gamma / k_{2}$ and $\beta_{1}=k_{4}{ }^{3} \beta_{0}$ respectively stands for the same parameter of the border girder.

Then, the girder displacement matrix under unit load $\left[\delta_{i p}{ }^{k}\right]$ can be described as follows

$$
\left[\delta_{i p}{ }^{k}\right]=\left[\begin{array}{cccccccccc}
-1 / k_{1} & 1 / k_{1} & 0 & 0 & 0 & 0 & 0 & 0 & 0 & 0 \\
0 & -1 / k_{1} & 1 & 0 & 0 & 0 & 0 & 0 & 0 & 0 \\
0 & 0 & -1 & 1 & 0 & 0 & 0 & 0 & 0 & 0 \\
0 & 0 & 0 & -1 & 1 & 0 & 0 & 0 & 0 & 0 \\
0 & 0 & 0 & 0 & -1 & 1 & 0 & 0 & 0 & 0 \\
0 & 0 & 0 & 0 & 0 & -1 & 1 & 0 & 0 & 0 \\
0 & 0 & 0 & 0 & 0 & 0 & -1 & 1 & 0 & 0 \\
0 & 0 & 0 & 0 & 0 & 0 & 0 & -1 & 1 / k_{1} & 0 \\
0 & 0 & 0 & 0 & 0 & 0 & 0 & 0 & -1 / k_{1} & 1 / k_{1} \\
0 & 0 & 0 & 0 & 0 & 0 & 0 & 0 & 0 & 0 \\
0 & 0 & 0 & 0 & 0 & 0 & 0 & 0 & 0 & 0 \\
0 & 0 & 0 & 0 & 0 & 0 & 0 & 0 & 0 & 0 \\
0 & 0 & 0 & 0 & 0 & 0 & 0 & 0 & 0 & 0 \\
0 & 0 & 0 & 0 & 0 & 0 & 0 & 0 & 0 & 0 \\
0 & 0 & 0 & 0 & 0 & 0 & 0 & 0 & 0 & 0 \\
0 & 0 & 0 & 0 & 0 & 0 & 0 & 0 & 0 & 0 \\
0 & 0 & 0 & 0 & 0 & 0 & 0 & 0 & 0 & 0 \\
0 & 0 & 0 & 0 & 0 & 0 & 0 & 0 & 0 & 0
\end{array}\right]
$$

Divided these flexibility coefficients by $w_{0}$ and take the results into Equation (1), the canonical equation can be obtained

$$
\left[\delta_{i j}\right] \cdot\left[g_{1}\right]+\left[\delta_{i p}{ }^{k}\right]=0
$$

Up to now, the redundant shear force $\left(g_{i}, M_{n}\right)$ in each section can be obtained through solving the matrix equation. Assuming that unit load acts at $1 \#$ girder, then the transverse distribution when loading at $1 \#$ girder can be calculated:

$$
\eta_{11}=1-g_{1}, \quad \eta_{21}=g_{1}-g_{2}, \quad \eta_{31}=g_{2}-g_{3}, \quad \ldots \quad \eta_{91}=g_{8}-g_{9}, \quad \eta_{10,1}=g_{9}
$$

Similarly, the load transverse distribution can be also calculated when the unit load acts at 2\# girder to 10\# girder. In this calculation method, the box-girder is divided into two T-girders with the bending stiffness and torsional stiffness equally distributed thus there are altogether $10 \mathrm{~T}$-girders rather than 6 . Therefore, the actual distribution of the box-girder is the sum of two T-girders. And the final results are listed in Table 1 where girders from left to 
right in cross section diagram (Figure 4) is numbered $1 \#$ to $8 \#$ in order and $\eta$ stands for the transverse distribution coefficient, similarly hereinafter.

Table 1 . The calculating result by the method in this paper

\begin{tabular}{ccccccccc}
\hline$\eta$ & $1 \#$ & $2 \#$ & $3 \#$ & $4 \#$ & $5 \#$ & $6 \#$ & $7 \#$ & $8 \#$ \\
\hline $1 \#$ & 0.749 & 0.562 & 0.450 & 0.338 & 0.236 & 0.148 & 0.080 & 0.010 \\
$2 \#$ & 0.075 & 0.089 & 0.081 & 0.069 & 0.054 & 0.039 & 0.026 & 0.011 \\
$3 \#$ & 0.060 & 0.081 & 0.084 & 0.078 & 0.067 & 0.053 & 0.039 & 0.020 \\
$4 \#$ & 0.045 & 0.069 & 0.078 & 0.082 & 0.077 & 0.067 & 0.054 & 0.031 \\
$5 \#$ & 0.031 & 0.054 & 0.067 & 0.077 & 0.082 & 0.078 & 0.069 & 0.045 \\
$6 \#$ & 0.020 & 0.039 & 0.053 & 0.067 & 0.078 & 0.084 & 0.081 & 0.060 \\
$7 \#$ & 0.011 & 0.026 & 0.039 & 0.054 & 0.069 & 0.081 & 0.089 & 0.075 \\
$8 \#$ & 0.010 & 0.080 & 0.148 & 0.236 & 0.338 & 0.450 & 0.562 & 0.749 \\
\hline
\end{tabular}

\subsection{FEM Analysis}

A finite element model on the basis of grillage theory is built using MIDAS/CIVIL to validate the accuracy of this calculation method (Figure 8). And the calculating result of load transverse distribution is listed in Table 2.

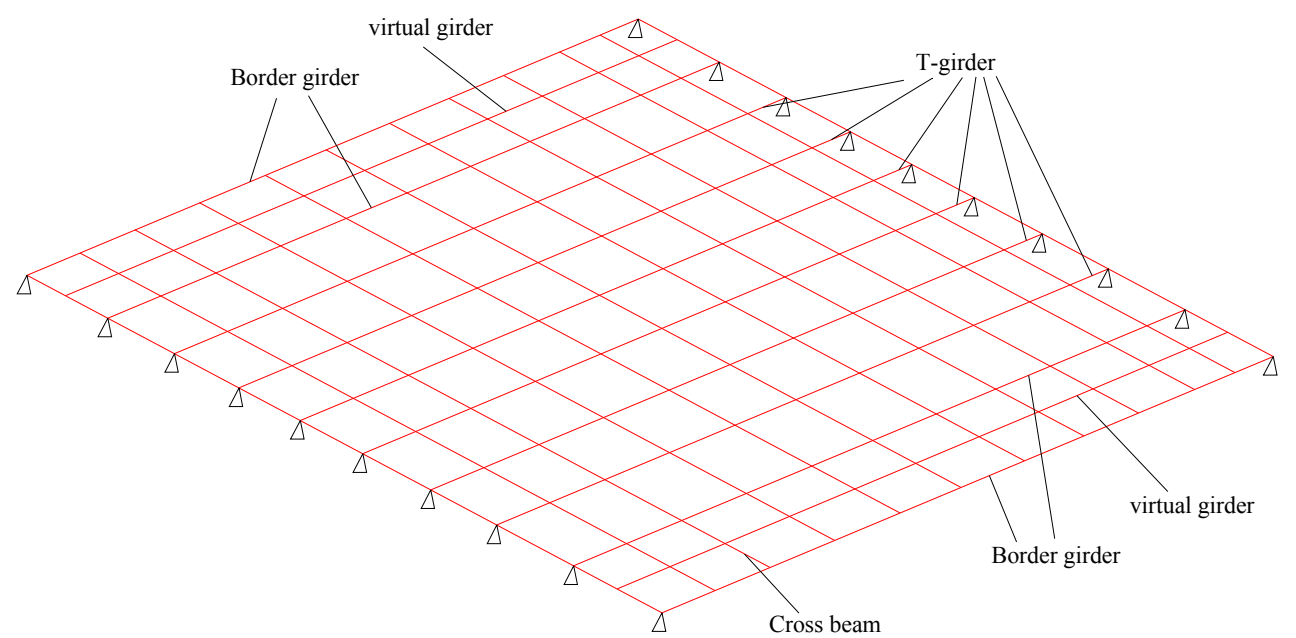

Figure 8 . The finite element model on the basis of grillage theory

Table 2. Calculating result of load transverse distribution by FEM

\begin{tabular}{ccccccccc}
\hline$\eta$ & $1 \#$ & $\# 2$ & $3 \#$ & $4 \#$ & $5 \#$ & $6 \#$ & $7 \#$ & $8 \#$ \\
\hline $1 \#$ & 0.767 & 0.608 & 0.524 & 0.421 & 0.305 & 0.193 & 0.097 & -0.032 \\
$2 \#$ & 0.085 & 0.046 & 0.039 & 0.044 & 0.049 & 0.045 & 0.032 & 0.005 \\
$3 \#$ & 0.069 & 0.047 & 0.039 & 0.042 & 0.053 & 0.060 & 0.053 & 0.019 \\
$4 \#$ & 0.052 & 0.055 & 0.045 & 0.041 & 0.046 & 0.056 & 0.060 & 0.035 \\
$5 \#$ & 0.035 & 0.060 & 0.056 & 0.046 & 0.041 & 0.045 & 0.055 & 0.052 \\
$6 \#$ & 0.019 & 0.053 & 0.060 & 0.053 & 0.042 & 0.039 & 0.047 & 0.069 \\
$7 \#$ & 0.005 & 0.032 & 0.045 & 0.049 & 0.044 & 0.039 & 0.046 & 0.085 \\
$8 \#$ & -0.032 & 0.097 & 0.193 & 0.305 & 0.421 & 0.524 & 0.608 & 0.767 \\
\hline
\end{tabular}


It can be concluded that the analytical results in this method conform well to the FEM results as shown in Figure 9(a)-(d), which proves that it is an effective way dividing the box-girder into two T-girders when calculating the load transverse distribution with large box girder whose deformation can't be neglected.
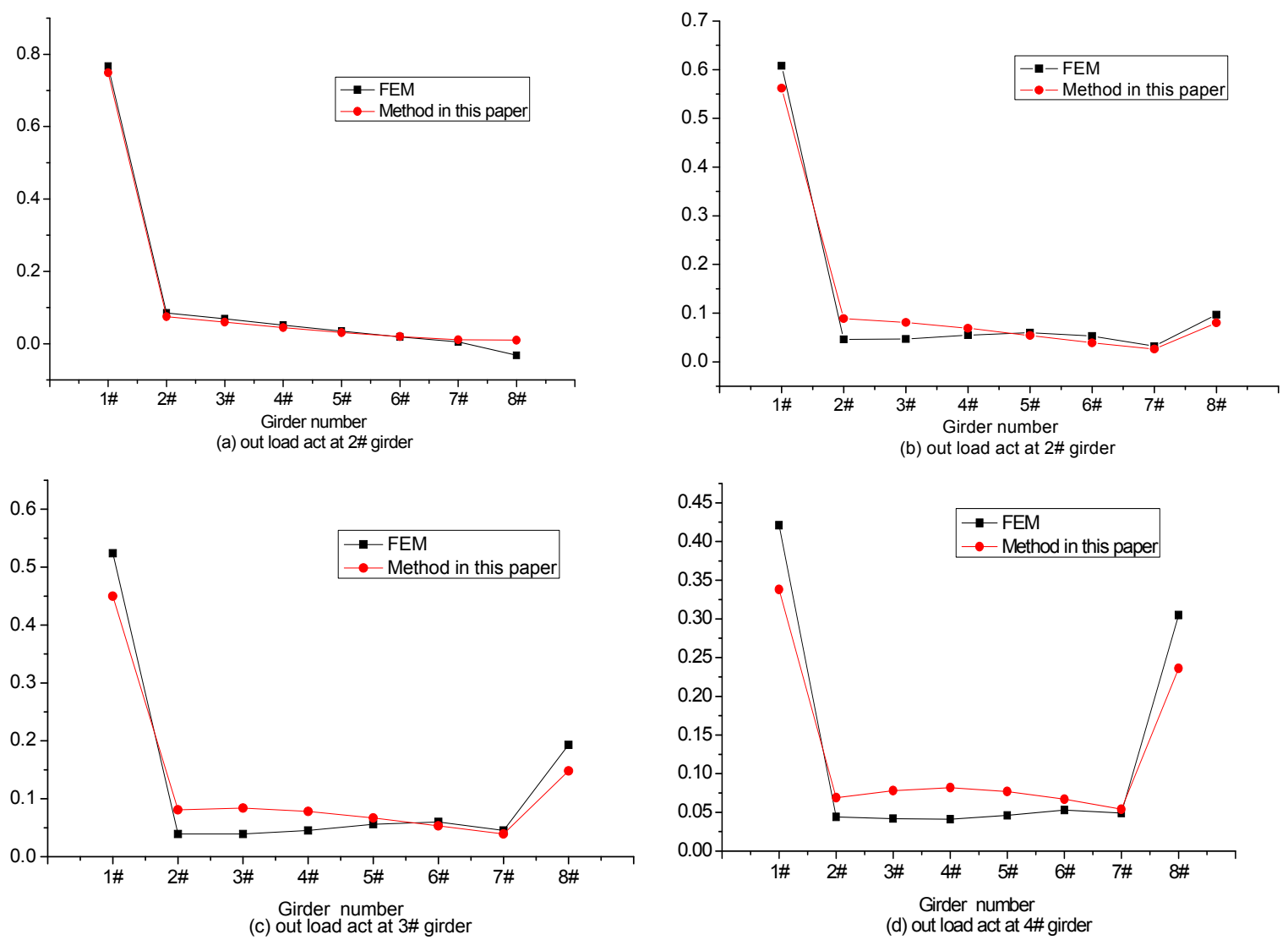

Figure 9. Transverse distribution when load act at different girders

\subsection{Comparison to the Transverse Distribution before Strengthened}

To explore the strengthening effects, the load transverse distribution of Yingjing Bridge before strengthened (Figure 3) are calculated by conventional rigid connected girder method and the calculation results are listed in Table 3 where girders from left to right in cross section diagram (Figure 3 ) is numbered $1 \#$ to $6 \#$ in order.

Table 3. Load transverse distribution of Yingiing Bridge before strengthening

\begin{tabular}{ccccccc}
\hline$\eta$ & $1 \#$ & $2 \#$ & $3 \#$ & $4 \#$ & $5 \#$ & $6 \#$ \\
\hline $1 \#$ & 0.471 & 0.347 & 0.225 & 0.104 & -0.015 & -0.133 \\
$2 \#$ & 0.347 & 0.276 & 0.203 & 0.13 & 0.058 & -0.015 \\
$3 \#$ & 0.225 & 0.203 & 0.181 & 0.156 & 0.13 & 0.104 \\
$4 \#$ & 0.104 & 0.13 & 0.156 & 0.181 & 0.203 & 0.225 \\
$5 \#$ & -0.015 & 0.058 & 0.13 & 0.203 & 0.276 & 0.347 \\
$6 \#$ & -0.133 & -0.015 & 0.104 & 0.225 & 0.347 & 0.471 \\
\hline
\end{tabular}



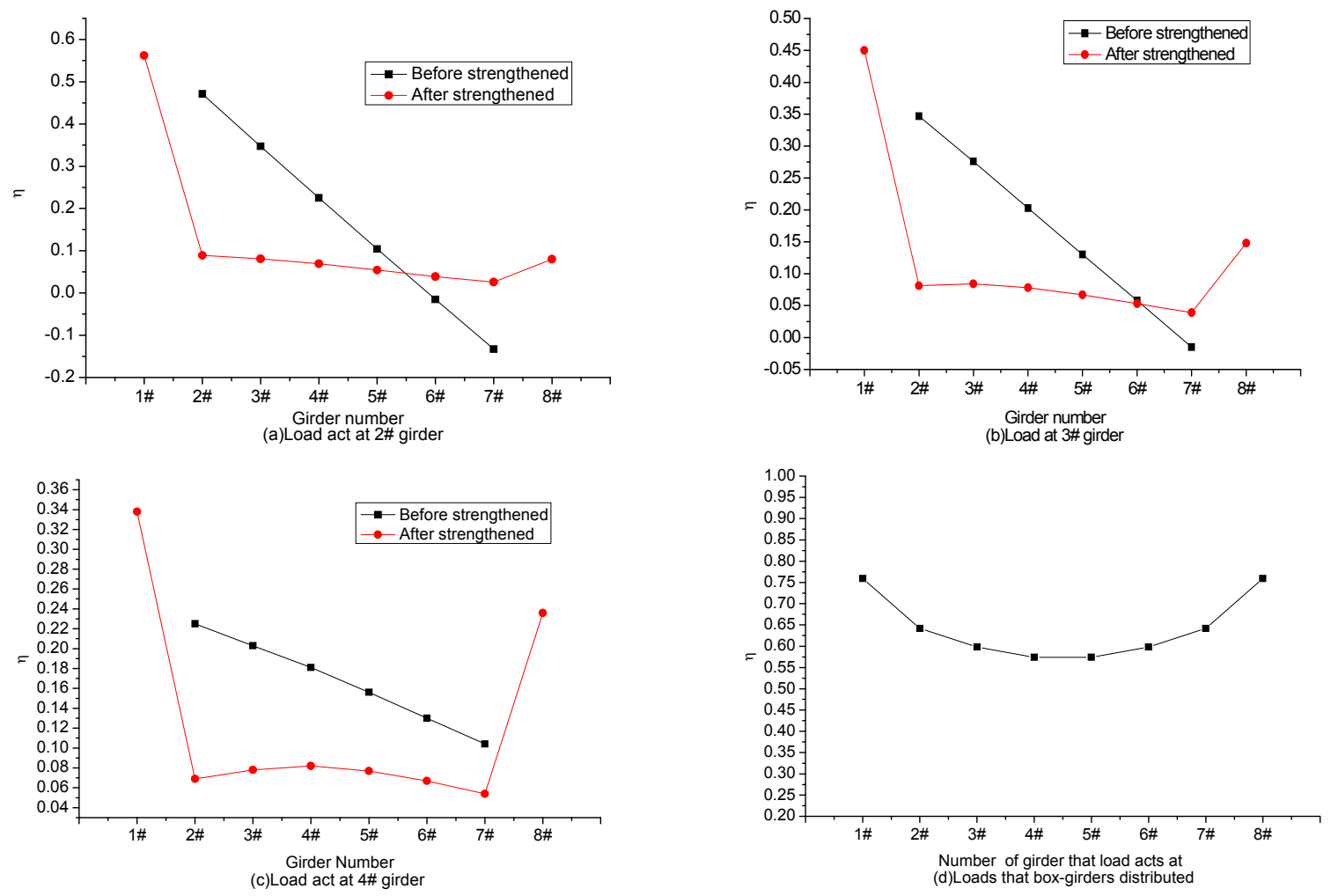

Figure 10. Analysis of strengthening effect

As shown in Table 3 and Figure 10(a)-(c), the loads distributed on T-girders after strengthened decrease greatly than the one before strengthened. Taking $2 \#$ girder as an example, the load distributed on $2 \#$ girder decreases from $34.7 \%$ to $8.9 \%$ when the load acts at $2 \#$ girder, that is, the girder has been efficiently unloaded due to the large border girder. Besides, the load distributed on added box-girders maintains stable, always being over 55\% wherever the load acts (Figure 10(d)), which further proves that adding box-girder to the original bridge is an effective strengthening way to avoiding cracks and improve the bearing capacity.

\section{Conclusions and Suggestion}

On the basis of analysis above, the following conclusions can be drawn

(a) The load transverse distribution calculation method proposed in this paper takes not only the size differences but also the box girder deformation into consideration, which is especially fit for the load transverse distribution calculation referred to large box-girder whose deformation can't be neglected.

(b) The accuracy of this calculation method is validated through an engineering example whose analytical results conform well to the FEM one.

(c) The comparisons between the loads transverse distributions before and after strengthened further prove that adding box-girder to the original bridge is an effective strengthening way to avoid cracks and improve the bearing capacity.

The load transverse distribution calculation method proposed in this paper can be used to calculate the load transverse distribution of bridge with large box-girder whose deformation can't be neglected. Though the results are correct, there still exists some simplifications and there is still a long way to go to expand its application range.

\section{References}

Fan, L. C. (2001). Bridge Engineering. Bejing: China Communications Press.

Hambly, E. C. (1982). Bridge Deck Behaviour (1st ed.). Beijing: People's Railway Press.

He, S. H., \& Xie, R. W. (1996). Calculation Method of Transverse Distribution in Highway Bridge. Bejing: China Communications Press. 
Li, G. H., \& Shi, D. (1977). Calculation of Load Transverse Distribution in Highway Bridge. Beijing: China Communications Press.

Nie, J., Zhang, X., Fan, J., Li, Y., \& Xu, R. (2010). Transverse Distribution Coefficient of Concrete Bridges Widened with Steel-concrete Composite Beams. Beijing: Journal of Tsinghua University (Natural Science Edition), 50(6), 805-809.

Wu, Q. X., \& Zheng, Z. F. (1997). The Simplified Calculation of Crosswise Loading Distribution of the Straight Beam Bridge with Large Skirt Beams. Fuzhou: Journal of Fuzhou University (Natural Science Edition), 25(2), 86-89.

Zhang, D. Q., Zhang, J. T., \& Fan, L. (2003). Investigation on Widening and Reinforcing the Yingjing Bridge by Installing a Box-Girder. Chongqing: Journal of Chongqing Architecture University, 25(1), 94-99.

Zhou, Z. X., \& Zhang, J. T. (1998). Widening and Strengthening Research on Yingjing Bridge. Beijing: Engineering Mechanics, A(02), 425-429.

\section{Copyrights}

Copyright for this article is retained by the author(s), with first publication rights granted to the journal.

This is an open-access article distributed under the terms and conditions of the Creative Commons Attribution license (http://creativecommons.org/licenses/by/3.0/). 